\title{
Development of phoma lesions on oilseed rape leaves inoculated with ascospores of A-group or B-group Leptosphaeria maculans (stem canker) at different temperatures and wetness durations
}

\author{
C. Toscano-Underwood ${ }^{a *}$, , J. S. West ${ }^{a}$, B. D. L. Fitt ${ }^{a}$, A. D. Todd ${ }^{a}$ and M. Jedryczka ${ }^{b}$ \\ a IACR-Rothamsted, Harpenden, Hertfordshire AL5 2JQ, UK; and ${ }^{\mathrm{b}}$ Institute of Plant Genetics, Polish Academy of Sciences, \\ Strzeszynska 34, 60-479 Poznan, Poland
}

\begin{abstract}
In controlled-environment experiments, ascospores of both A-group and B-group Leptosphaeria maculans were able to infect leaves of oilseed rape and produce phoma leaf spot lesions at temperatures from 5 to $20^{\circ} \mathrm{C}$ and wetness durations from 8 to $72 \mathrm{~h}$ after inoculation. Lesions formed on leaves inoculated with B-group ascospores had few pycnidia and were darker, smaller and less noticable than the larger, pale grey lesions with many pycnidia produced by A-group ascospores. Lesions formed by A-group or B-group L. maculans on naturally infected winter oilseed rape experimental crops were similar to lesions produced by the two groups on inoculated plants. The greatest numbers of lesions were produced with a leaf wetness duration of $48 \mathrm{~h}$ and at temperatures of $15-20^{\circ} \mathrm{C}$ for both A-group and Bgroup ascospores. As leaf wetness duration and temperature decreased below the optimal values, the number of lesions decreased. The incubation period, estimated as the time from inoculation to the appearance of the first lesions $\left(t_{1}\right)$, or the time to the appearance of $50 \%$ of the lesions $\left(t_{50}\right)$, of B-group was often shorter than that of A-group L. maculans. As temperature decreased below $20^{\circ} \mathrm{C}$, the length of the incubation period of both A-group and B-group L. maculans increased.
\end{abstract}

Keywords: ascospores, incubation period, infection conditions, Leptosphaeria maculans, phoma leaf spot, stem canker, winter oilseed rape

\section{Introduction}

Stem canker or blackleg is one of the most important diseases on winter oilseed rape in the UK (Fitt et al., 1997). This damaging disease is caused by Leptosphaeria maculans (anamorph Phoma lingam) and affects oilseed rape (Brassica napus ssp. oleifera) worldwide. In eastern and southern England, widespread, severe attacks of stem canker were first observed on crops of susceptible winter oilseed rape cultivars in 1977 and 1978. Throughout the 1980s the incidence of severe stem canker epidemics gradually decreased. Since 1993, however, severe, widespread epidemics have again been reported on crops in eastern England (Gladders \& Symonds, 1995; Gladders et al., 1998). In the UK, the disease can cause yield losses of up to $50 \%$ in susceptible cultivars when incidence of severe

*To whom correspondence should be addressed.

†E-mail: claudia.underwood@bbsrc.ac.uk

Accepted 20 July 2000. stem canker (stem base lesions) is high (Gladders \& Musa, 1979). Recent investigations (Zhou et al., 1999) suggest that yield loss is related to incidence and severity of both basal stem cankers and upper stem lesions.

Severe basal cankers originate from infections on leaves at the rosette stage of crop growth in the autumn, initiated by airborne ascospores released from infected oilseed rape debris (Gladders \& Musa, 1980). Lesions higher up the stem originate from infections on leaves produced later in the season. Under favourable conditions, ascospores of the pathogen infect leaves and produce lesions (phoma leaf spots) from which it grows systemically down the petiole into the stem to initiate basal stem canker or upper stem lesions (Hammond et al., 1985). Results from field experiments indicate that once in the stem, L. maculans can no longer be controlled effectively by fungicide applications (Gladders et al., 1998; West et al., 1999). Therefore there is a need to prevent the pathogen from reaching the stem, by fungicide applications in the autumn, for the effective control of stem canker in spring and summer (Gladders et al., 1998). To optimize the timing of fungicide 
applications for control of stem canker, infection conditions for L. maculans ascospores need to be better understood.

The variability of $L$. maculans populations from different geographical locations has been well documented (McGee \& Petrie, 1978; Humpherson-Jones, 1983; 1986; Somda et al., 1996; Jedryczka et al., 1999). There are two genetically distinct subpopulations of the fungus, which may be different species (Williams, 1992). These two groups have been described as aggressive and nonaggressive (Koch et al., 1989) and more recently as A-group and B-group (Johnson \& Lewis, 1990, Johnson \& Lewis, 1994) or $\mathrm{Tox}^{+}$and Tox $^{0}$ (Balesdent et al., 1992). A-group (aggressive, $\mathrm{Tox}^{+}$) and B-group (nonaggressive, Tox ${ }^{0}$ ) isolates differ in cultural, biochemical and molecular characteristics and in their ability to produce stem cankers on oilseed rape (Koch et al., 1989; Johnson \& Lewis, 1990; Taylor et al., 1991; Balesdent et al., 1992; Brun et al., 1997). A-group isolates are characterized by slow growth in vitro, absence of water-soluble pigments in liquid culture, and ability to synthesize a group of phytotoxins named sirodesmins. B-group isolates grow more rapidly in vitro, accumulate a yellow-brown pigment in culture, and are unable to produce sirodesmins. In addition, while A-group isolates cause severe basal stem cankers, B-group isolates have been predominantly associated with damage to stem pith tissue in the UK (Johnson \& Lewis, 1994). To avoid repetitive listings of other descriptions, the terms A-group and B-group will be used in this paper.

In the UK, both A-group and B-group isolates are present in L. maculans populations in winter oilseed rape crops (Humpherson-Jones, 1983; Humpherson-Jones, 1986; Hammond \& Lewis, 1986; Johnson \& Lewis, 1994). Although some geographical variation in the frequencies of the two groups may occur, recent studies suggest that the A-group is now predominant in UK populations of the fungus (Jedryczka et al., 1999). By contrast, in Poland the B-group predominates in L. maculans populations on winter oilseed rape, with the A-group comprising only $5 \%$ of the populations (Jedryczka et al., 1997, Jedryczka et al., 1999). Changes in the proportions of isolates of the two groups present with position on the oilseed rape stem have been reported in Germany; the A-group was predominant on the stem base, and a greater proportion of the B-group was present on the upper stem (Thürwächter et al., 1999). Similar changes in the proportions of the two groups with position on the stem have been observed in France (J. Schmidt, INRA, Versailles, France, personal communication). Hitherto, little was understood about the differences in epidemiology between the two groups of L. maculans. Johnson \& Lewis (1994) reported the progress of natural epidemics caused by mixtures of A-group and B-group $L$. maculans in winter oilseed rape crops in the UK during the $1989 / 1990$ season. Their results suggest that the leaf infection process for the A-group and B-group is similar in natural mixed populations, but the timing of the epidemic may differ between the two groups.
Studies on epidemics of L. maculans in winter oilseed rape crops in the UK suggest that the disease is predominantly monocyclic (Hammond \& Lewis, 1986). Ascospores are the primary source of inoculum (Gladders \& Musa, 1980), and in the UK there is little secondary spread by rain-splashed conidia produced on primary phoma leaf spot lesions. Differences in disease severity occur between sites and seasons, and may be partially attributed to differences in weather conditions (in particular temperature and rainfall) favourable for infection of leaves by ascospores of the fungus. Few experiments have used L. maculans ascospores as inoculum on oilseed rape leaves. Recent work on infection conditions for ascospores of A-group $L$. maculans (Biddulph et al., 1999a) suggests that both temperature and leaf wetness duration affect the maximum number of leaf lesions and the incubation period (time from infection to the appearance of lesions) of the fungus. However, little is known about the infection criteria for ascospores of the B-group of $L$. maculans (Biddulph et al., 1999b). This paper compares the effects of temperature and wetness duration on the infection of oilseed rape leaves by ascospores of Agroup or B-group L. maculans and the subsequent development of phoma leaf spot lesions.

\section{Materials and methods}

Four experiments were carried out in controlledenvironment cabinets. The factors tested are listed in Table 1 . The cabinets used were: a Fisons $600 \mathrm{H}$ cabinet (dimensions $1.2 \times 0.6 \times 0.8 \mathrm{~m}$ ) with fluorescent lighting giving a light intensity of $210 \mu \mathrm{e} \mathrm{m}^{-2} \mathrm{~s}^{-1}$ at plant canopy level and a relative humidity of $55-90 \%$; a Sanyo PG 660 cabinet $(1.2 \times 0.6 \times 0.9 \mathrm{~m})$ with a light intensity of $200 \mu \mathrm{e} \mathrm{m}^{-2} \mathrm{~s}^{-1}$ and a relative humidity of $50-95 \%$; the other four cabinets were designed at Rothamsted $(2.5 \times 1.0 \times 1.35 \mathrm{~m})$ with a light intensity of $210 \mu \mathrm{e} \mathrm{m}^{-2} \mathrm{~s}^{-1}$ and $80-85 \%$ relative humidity. A daylength of $12 \mathrm{~h}$ was maintained during experiments. There were four pots per temperature/wetness duration treatment, with each pot containing one plant. The four pots for a wetness duration treatment were all placed in one seed tray $(22 \times 36 \mathrm{~cm})$. The same temperatures were maintained for the wetness period after inoculation and the subsequent incubation period until symptoms developed. Seed trays (wetness duration treatments) were arranged in completely randomized designs in each growth cabinet (temperature treatment). Cabinets for temperature treatments were allocated randomly whenever possible, but some cabinets could not operate at the lower temperatures $\left(5\right.$ and $\left.10^{\circ} \mathrm{C}\right)$. The temperature in the cabinets was monitored throughout the experiments and found to vary by $\pm 1^{\circ} \mathrm{C}$. The series of experiments was arranged in a split-plot design, with temperatures (in different cabinets) as the main plots replicated in time (four replicates, expts 1, 2, 3 and 4) and $L$. maculans group/wetness duration treatments as subplots. 
Table 1 Treatment factors, tissues and controlled environment cabinets used in each of four experiments to investigate the effects of infection conditions on the development of phoma leaf spot (Leptosphaeria maculans) lesions on oilseed rape leaves (cultivar Lipton)

\begin{tabular}{|c|c|c|c|c|}
\hline \multirow[b]{2}{*}{ Experiment } & \multicolumn{4}{|c|}{ Infection condition treatments } \\
\hline & Temperature $^{a}\left({ }^{\circ} \mathrm{C}\right)$ & Wetness duration (h) & Tissue & Cabinets $^{a}$ \\
\hline 1 & $5,10,15,20$ & $8,16,24,48,72$ & Leaves 1-4 & $A, B, C, D$ \\
\hline 2 & $5,10,15,20$ & $8,16,24,48,72$ & Leaves 1-4 & $A, E, C, D$ \\
\hline 3 & $5,10,20$ & $8,16,24,48,72$ & Leaves 1-4 & $A, F, D$ \\
\hline 4 & $5,10,15$ & $8,16,24,48,72$ & Leaves 1-4 & $A, F, D$ \\
\hline
\end{tabular}

${ }^{a}$ Cabinets and temperature treatments are in order of increasing temperature; cabinets were allocated randomly to temperature treatments whenever it was possible, but cabinets $\mathrm{C}$ and $\mathrm{D}$ could not operate at temperatures $<15^{\circ} \mathrm{C}$. A was a Sanyo PG 660 cabinet; $\mathrm{B}$, a Fisons $600 \mathrm{H}$ cabinet; C-F, Rothamsted-designed cabinets.

\section{Plant material}

Seeds of winter oilseed rape cv. Lipton, moderately resistant to stem canker (NIAB resistance score 5) (Anonymous, 1997), were sown in Jiffy pots containing peat-based compost, a soluble fertilizer $(1.5 \mathrm{~kg}$ PG mix $\left.\mathrm{m}^{-3}\right)$ and a slow-release fertilizer $\left(2 \mathrm{~kg}\right.$ Osmocote $\left.\mathrm{m}^{-3}\right)$ (Petersfield Products, Cosby, Leicester, UK). Plants were grown initially in a glasshouse and were transplanted into $9 \mathrm{~cm}$ diameter pots (one plant per pot) 15 days after sowing. Three days (expts 1, 3 and 4) or 1 day (expt 2) prior to inoculation, four of the pots were transferred to each of the seed trays, which were kept filled with water (depth $1 \mathrm{~cm}$ ) throughout the experiments. These trays were then placed in controlledenvironment cabinets at 10 or $15^{\circ} \mathrm{C}$ to acclimatize the plants. After inoculation, trays were transferred to the controlled-environment cabinets for each temperature treatment. Each plant had three true leaves fully expanded, with the fourth leaf just starting to expand (GS 1,4; Sylvester-Bradley \& Makepeace, 1985) at the time of inoculation. Each leaf was numbered using a nonphytotoxic marker pen.

\section{Identification of A-group and B-group L. maculans using ascospores}

Pieces (approximately 20-50 cm long) of winter oilseed rape stem debris (cv. Lipton) showing stem canker lesions were collected after harvest from fields at Rothamsted, UK and at Poznan, Poland. These stem pieces were expected to produce ascospores which were predominantly of A-group or B-group L. maculans, respectively (Jedryczka et al., 1999). All stem pieces were placed in plastic trays $(45 \times 75 \mathrm{~cm})$ and left outdoors under natural conditions for approximately 2 months until pseudothecia classed as mature (Poisson \& Pérès, 1999) had developed. Stem pieces containing mature pseudothecia were stored dry at $-5^{\circ} \mathrm{C}$ until required.

To confirm the identity of the ascospore inoculum used (A-group or B-group), single ascospore cultures were produced from UK or Polish stem debris by attaching sections of stem $(3-4 \mathrm{~cm}$ long), bearing mature pseudothecia, to the underside of $9 \mathrm{~cm}$ Petri dish lids with petroleum jelly (Vaseline). The stem sections were moistened with distilled water to induce ascospore release, and the lids were placed over Petri dish bases containing $1 \% \mathrm{w} / \mathrm{v}$ distilled water agar. The Petri dishes were incubated at approximately $20^{\circ} \mathrm{C}$ (room temperature) and ascospore release was monitored every hour using a binocular microscope. Single ascospores which were entirely separate from other spores and mycelium were cut from the agar using a sterile scalpel and transferred to new Petri dishes containing $4 \% \mathrm{w} / \mathrm{v}$ potato dextrose agar (PDA). These were incubated at $20^{\circ} \mathrm{C}$ for 10 days and were assessed as A-group or B-group, based on colony growth rate and pigment production. Colonies considered to be Bgroup had a faster growth rate than A-group colonies and produced a distinctive yellow pigment (Williams \& Fitt, 1999).

UK stem pieces from the tap root and stem base $(<10 \mathrm{~cm}$ above ground level) were found to produce predominantly A-group ascospores (57 A-group : three B-group isolates), but pieces from upper stems (10$30 \mathrm{~cm}$ above ground level) produced a much greater proportion of B-group ascospores (12 A-group : 15 Bgroup isolates). Consequently, only the stem base and tap root region of UK stem debris were used for producing A-group ascospore inoculum. Polish stem debris was found to produce only B-group ascospores (36 out of 36 isolations made), and this was therefore used for producing B-group ascospore inoculum (as it would not have been possible to obtain pure B-group inoculum from UK debris).

\section{Inoculation}

To obtain ascospores for inoculating plants in controlled-environment experiments, 3-4 cm stem lengths bearing mature pseudothecia were attached with petroleum jelly to the underside of $9 \mathrm{~cm}$ diameter Petri dish lids. The pieces of stem were flooded with distilled water for $30 \mathrm{~s}$ to swell the asci, then the water was poured off and the lid placed over the Petri dish base. After a period of $1 \mathrm{~h}$ at room temperature $\left(\approx 20^{\circ} \mathrm{C}\right)$ followed by $1 \mathrm{~h}$ at $5^{\circ} \mathrm{C}$, large numbers of 
ascospores had been discharged into the dishes. Sterile distilled water $(2.5 \mathrm{~mL})$ with added Tween $80(0.05 \%)$, cooled to $0^{\circ} \mathrm{C}$ to retard spore germination, was added to each Petri dish, and the spores were dislodged using a sterile wooden spatula. Ascospore suspensions from several dishes were combined and the concentration of spores adjusted using a haemocytometer. Suspensions were kept frozen $\left(-5^{\circ} \mathrm{C}\right)$ for up to 3 weeks prior to inoculation. Before inoculation, suspensions were allowed to thaw and the spore concentration was readjusted using a haemocytometer.

Potted plants were inoculated with suspensions of L. maculans ascospores $10^{3} \mathrm{~mL}^{-1}$ by spraying with an aerosol pressurized sprayer (Chromatomiser, Camlab Ltd, Cambridge, UK) until leaf surfaces were uniformly covered with droplets. This ascospore concentration had previously been shown to produce an adequate number of leaf lesions (Biddulph et al., 1999a). Immediately after inoculation, wetness duration treatments were applied by covering plants with polyethylene bags previously sprayed inside with distilled water. Plants were given wetness periods of 8, 16, 24 and $48 \mathrm{~h}$ at temperatures of 15 and $20^{\circ} \mathrm{C}$, and 16,24 , 48 and $72 \mathrm{~h}$ at temperatures of 5 and $10^{\circ} \mathrm{C}$. After wetness periods the polyethylene bags were removed.

The infection efficiency of A-group and B-group $L$. maculans ascospores was estimated in expt 3. At the time of inoculation, five microscope slides each were sprayed with A-group or B-group L. maculans ascospore suspension used as inoculum for the experiment. The number of ascospores deposited per $\mathrm{cm}^{2}$ on each of the 10 slides was counted. The areas of leaves of 10 additional uninoculated plants were measured (four leaves per plant). The mean number of ascospores deposited per unit leaf area was calculated. This was later related to the mean number of lesions that developed on leaves of plants maintained under nearoptimal conditions (temperature $20^{\circ} \mathrm{C}$; leaf wetness duration $48 \mathrm{~h}$ after inoculation).

The percentage germination of A-group and B-group L. maculans ascospores was also estimated in expt 3 . Prior to inoculation, ascospore suspensions used as inoculum for the experiment were shaken vigorously and a drop of A-group or B-group ascospore suspension was placed on $1 \%$ distilled water agar in each of five Petri dishes and spread on the agar with a sterile glass rod. Agar dishes were incubated at room temperature for $24 \mathrm{~h}$, after which they were observed under a binocular microscope to assess the percentage of germinated ascospores. The mean number of germinated ascospores, out of a total of 50 ascospores counted on each of the five replicate dishes, and the percentage germination of the ascospores were calculated.

\section{Disease assessments}

The numbers of new phoma leaf spots on each of the first four true leaves were counted almost daily until either the leaves died (temperatures $15^{\circ} \mathrm{C}$ and $20^{\circ} \mathrm{C}$ ) or no new leaf spots appeared (temperatures 5 and $10^{\circ} \mathrm{C}$ ), up to 32 days after inoculation. The incubation period was estimated as either the time from inoculation until the first lesions were observed (calculated as the mean of the last time when no lesions were present and the first time when lesions were present), or the time until $50 \%$ of the lesions were observed.

\section{Isolation from inoculated plants and naturally infected crops}

At the end of expts 1, 2 and 4, isolations were made from lesions on leaves of 20 plants: 10 plants inoculated with A-group ascospores and 10 plants inoculated with B-group ascospores. Infected leaves from plants kept at near-optimal conditions (temperature 15 or $20^{\circ} \mathrm{C}$, wetness duration $48 \mathrm{~h}$ ) were excised (two or three leaves per plant) and surface sterilized by immersion for $2 \mathrm{~min}$ in sodium hypochlorite solution $(0 \cdot 2 \%$ available chlorine). Small areas of the lesions adjacent to the edge were then cut out with a sterile scalpel, transferred to $1 \%$ distilled water agar and incubated at room temperature. One week later, small blocks of agar containing fungal hyphae growing from excised leaf sections were cut with a sterile scalpel, transferred to Petri dishes of $4 \%$ PDA (Oxoid, Basingstoke, UK) supplemented with penicillin $\left(20\right.$ units $\left.\mathrm{mL}^{-1}\right)$ and streptomycin (40 units $\mathrm{mL}^{-1}$ ) and incubated at $20^{\circ} \mathrm{C}$ for 10 days. Plates were assessed every 2-3 days for colony growth and pigment production.

Leaf lesions produced on winter oilseed rape crops (cv. Lipton) by natural infection were compared with those observed in controlled-environment experiments. Leaves were collected from untreated field plots at Rothamsted in the autumn/winter of the 1998/99 and $1999 / 2000$ seasons, and isolations were made from a range of different lesion types.

\section{Statistical analyses of experimental data}

Data for the maximum number of lesions per leaf in all four experiments were $\log _{10}$-transformed before analyses to improve the homogeneity of variance. The effects of temperature and leaf wetness duration, and the interaction between them, on the maximum number of lesions produced by A-group and B-group $L$. maculans were analysed by restricted maximum likelihood estimation (REML) (Payne et al., 1993). REML was used to allow for estimation of variability due to plants, trays and cabinets within the unbalanced experimental structure (unequal treatment replication over time). Wald tests were used to assess treatment effects. Mean values for $\log _{10}$-transformed data were calculated and back-transformed. Incubation period data for the two measures of incubation period were analysed by REML, and Wald tests were used to estimate the effects of temperature and leaf wetness duration and their interactions. 


\section{Gompertz curves}

Three-parameter Gompertz curves:

$$
N=c \exp \{-\exp [-(l . e / c)(t-m)]\}
$$

(where $e=2 \cdot 718$, the base of the natural logarithm) were fitted using GENSTAT $4 \cdot 1$ to scaled data for the number of lesions per leaf $(N)$ on different days after inoculation $(t)$ to describe disease progress with time. For each temperature/leaf wetness treatment, data for number of lesions per leaf from the four experiments were scaled to the predicted mean maximum number of lesions for that treatment. Data were scaled to give comparable data sets and enable parameters to be estimated. The fitted Gompertz curves enabled estimates to be made of the three parameters, maximum number of lesions per leaf $(c)$, maximum rate of increase in the number of lesions per leaf per day $(l)$, and the day on which the number of lesions per leaf was maximum $(m)$, for each temperature and leaf wetness duration.

\section{Results}

\section{Isolations from inoculated plants and naturally infected crops}

A-group colonies (slower growth on PDA and lack of pigment production in culture) developed from all lesions on leaves inoculated with A-group (UK) ascospores (44 out of 44 isolations made). B-group colonies (faster growth on PDA and production of a yellow pigment in culture) developed from all lesions on leaves inoculated with B-group (Polish) ascospores (60 out of 60 isolations made). On naturally infected experimental oilseed rape crops, isolations made from large, pale grey leaf lesions containing abundant pycnidia produced A-group L. maculans. Isolations from small, dark lesions with few pycnidia usually produced B-group L. maculans (Table 2). A small number of large, brown leaf lesions without pycnidia were observed; isolations made from these produced Alternaria spp.

\section{Leaf lesion characteristics}

The type of lesions formed on oilseed rape leaves inoculated with ascospores and maintained in controlledenvironment conditions differed noticably between Agroup or B-group L. maculans. The predominant leaf lesions observed on plants inoculated with A-group ascospores started as diffuse, light grey patches that later developed into pale grey/green lesions with many pycnidia (Fig. 1a). Lesions formed on plants inoculated with Bgroup ascospores started as very small pin-points that later expanded slightly to form small, dark lesions or lesions with a dark margin and light brown centre, with few pycnidia (Fig. 1b). A number remained as pinpoint lesions on plants inoculated with ascospores of either group, and were taken to be indicative of noncompatible reactions. The number of pin-point lesions was generally greater on plants inoculated with B-group ascospores. Isolations showed that lesions formed by A-group (large, pale grey lesions) or Bgroup (smaller lesions with a dark margin) L. maculans on naturally infected crops were generally similar to those produced by the two groups on inoculated plants (Fig. 1c). However, some overlap in leaf symptoms between the two groups was observed at Rothamsted; on a few occasions, B-group L. maculans also produced large, pale grey lesions (Fig. 1c).

\section{Development of phoma leaf spot lesions}

Ascospores of both A-group and B-group L. maculans were able to infect leaves of oilseed rape and cause phoma leaf spot lesions at temperatures from 5 to $20^{\circ} \mathrm{C}$ (Table 3, Table 4; Fig. 3) and leaf wetness durations from 8 to $72 \mathrm{~h}$ (Table 3; Table 4, Fig. 4). Effects of temperature and leaf wetness duration on the pattern of leaf spot lesion development with time were similar in all four experiments and for both A-group and B-group L. maculans (Fig. 2). For both groups, the total number of leaf lesions that developed following inoculation differed between individual experiments, possibly because of differences between experiments in the percentage germination of the natural ascospores used as inoculum.

\section{Maximum number of lesions}

Temperature (Wald statistic 27.0, 3 d.f.; $P<0 \cdot 01$ ) and leaf wetness duration $(129 \cdot 8,4$ d.f.; $P<0 \cdot 01)$ affected the maximum number of lesions that developed on plants inoculated with ascospores of both A-group and B-group L. maculans, but the interaction between temperature and leaf wetness duration was not significant (11·6, 8 d.f.) (Table 3). Plants inoculated with A-group ascospores developed most lesions at $15^{\circ} \mathrm{C}$ and a leaf wetness duration of $48 \mathrm{~h}$ ( $>22$ lesions per leaf) (Table 3). Numbers of lesions were fewer at $20^{\circ} \mathrm{C}$ than at $15^{\circ} \mathrm{C}$ and decreased with decreasing temperature from 15 to $5^{\circ} \mathrm{C}$. The number of lesions decreased as leaf wetness duration decreased from 72 to $8 \mathrm{~h}$; very few lesions developed with a leaf wetness duration of $8 \mathrm{~h}$, and they were mostly at $15^{\circ} \mathrm{C}$. The Gompertz curves fitted well to the data for maximum number of lesions per leaf with time (days) after inoculation with A-group ascospores (Figs 3 and 4; Table 4). The parameter $c$ (maximum number of lesions per leaf) was affected by temperature and leaf wetness duration (Table 4). The values of $c$ were greater at 15 than at $20^{\circ} \mathrm{C}$, and decreased with decreasing temperature from 15 to $5^{\circ} \mathrm{C}$ (Fig. 3; Table 4). The value of $c$ decreased as leaf wetness duration decreased from 72 to $8 \mathrm{~h}$ (Fig. 4; Table 4).

Plants inoculated with B-group ascospores developed most lesions at temperatures of 15 and $20^{\circ} \mathrm{C}$ with a leaf wetness duration of $48 \mathrm{~h}$ (more than four lesions per leaf) (Table 3 ). The numbers of lesions produced decreased as temperature decreased from 15 to $5^{\circ} \mathrm{C}$ and as leaf wetness duration decreased from 72 to $8 \mathrm{~h}$; 


\begin{tabular}{lll}
\hline Sample date & $\begin{array}{l}\text { Isolations from large, pale grey } \\
\text { lesions with many pycnidia }\end{array}$ & $\begin{array}{l}\text { Isolations from small, dark } \\
\text { lesions with few pycnidia }\end{array}$ \\
\hline 20 Nov 1998 & 5/6 A-group ${ }^{a}$ & $2 / 4$ B-group \\
& 1/6 Fusarium spp. & $1 / 4$ A-group \\
& & $1 / 4$ Alternaria spp. \\
09 Feb 1999 & 8/8 A-group & $2 / 3$ B-group \\
13 Dec 1999 & 10/10 A-group & $1 / 3$ A-group \\
10 Feb 2000 & 8/10 A-group & $10 / 10$ B-group \\
& 2/10 unidentified & $1 / 3$ B-group \\
\end{tabular}

Table 2 Species of fungi isolated from typical phoma lesions on leaves of winter oilseed rape plants (cultivar Lipton) from field experiments at Rothamsted, UK

a'Leptosphaeria maculans.

very few lesions developed with leaf wetness durations of 16 and $8 \mathrm{~h}$, and they were mostly at $15^{\circ} \mathrm{C}$. The Gompertz curves fitted well to the data for changes in maximum number of lesions per leaf with time (days) after inoculation with B-group ascospores (Figs 3 and 4; Table 4), with the exception of the $20^{\circ} \mathrm{C} / 8 \mathrm{~h}$ leaf wetness duration treatment, for which too few lesions developed to fit a curve. As with the A-group, parameter $c$ was affected by temperature and leaf wetness duration. The values of $c$ were greater at 15 than at $20^{\circ} \mathrm{C}$ and decreased from 15 to $5^{\circ} \mathrm{C}$ (Fig. 3; Table 4). The value of $c$ decreased as leaf wetness duration decreased from 72 to 8 h (Fig. 4; Table 4). The total number of lesions that developed on plants inoculated with A-group ascospores was higher than on those inoculated with B-group ascospores for all treatment combinations tested under controlled-environment conditions (Wald statistic 44.0, 1 d.f.; $P<0 \cdot 01$ ) (Table 3).

In expt 3, the mean leaf area of plants at the time of inoculation (four leaves per plant; 10 plants) was $27 \cdot 8 \mathrm{~cm}^{2}$. The estimated mean number of ascospores of A-group or B-group L. maculans deposited per leaf was 83.4 (three ascospores $\mathrm{cm}^{-2}$ ). The mean number of lesions per leaf on plants inoculated with ascospores of A-group L. maculans and maintained at near-optimal conditions (temperature $20^{\circ} \mathrm{C}$, leaf wetness duration $48 \mathrm{~h}$ after inoculation) was $9.8\left(0.35\right.$ lesions $\left.\mathrm{cm}^{-2}\right)$. Thus the estimated efficiency of infection for ascospores of A-group L. maculans was 12\% (about one out of eight ascospores on the leaf surface caused a lesion under near-optimal conditions). The mean number of lesions per leaf on plants inoculated with ascospores of B-group L. maculans and maintained under nearoptimal conditions (temperature $20^{\circ} \mathrm{C}$, leaf wetness duration $48 \mathrm{~h}$ after inoculation) was 5.9 (0.21 lesions $\mathrm{cm}^{-2}$ ). Thus the estimated efficiency of infection for ascospores of B-group L. maculans was 7\% (about one out of 14 ascospores on the leaf surface produced a lesion under near optimal conditions). The percentage germination of ascospores of A-group L. maculans was $90 \%$ compared with $92 \%$ for the B-group ascospores.

\section{Incubation period}

Temperature (Wald statistic 107.4, 3 d.f.; $P<0 \cdot 01$ ) affected the incubation period, estimated as the time from inoculation to the appearance of the first lesions $\left(t_{1}\right)$. As temperature increased, the time to the appearance of the first lesion decreased greatly from $\approx 13-$ 15 days (A-group) and $\approx 14-16$ days (B-group) at $5^{\circ} \mathrm{C}$, to $\approx 3-4$ days (A-group) and $\approx 2-8$ days (B-group) at $20^{\circ} \mathrm{C}$ (Table 5). $t_{1}$ was shorter for B-group ascospores than for A-group at the following temperature/wetness treatments $\left({ }^{\circ} \mathrm{C} / \mathrm{h}\right): 10 / 48,10 / 72,15 / 8,15 / 16,15 / 48,20 /$ 16, 20/24 and 20/48 (Table 5; Figs 3 and 4), although the overall difference in $t_{1}$ between the two groups was not significant.

Temperature (Wald statistic 205.8, 3 d.f.; $P<0 \cdot 01$ ), L. maculans group (30.6, 1 d.f.; $P<0 \cdot 01)$ and wetness duration (11.7, 4 d.f.; $P<0.05)$ affected the length of the incubation period, estimated as the time from inoculation to the appearance of $50 \%$ of the lesions $\left(t_{50}\right)$. As temperature increased, the time to the appearance of $50 \%$ of lesions decreased from $\approx 19$ 24 days (A-group) and $\approx 17-19$ days (B-group) at $5^{\circ} \mathrm{C}$, to $\approx 5-8$ days (A-group) and $\approx 4-9$ days (B-group) at $20^{\circ} \mathrm{C}$. The estimated $t_{50}$ values were shorter for B-group than for A-group ascospores for all temperature/wetness duration treatments, except at $10^{\circ} \mathrm{C} / 24 \mathrm{~h}$ and $20^{\circ} \mathrm{C} /$ $16 \mathrm{~h}$ (Table 5). The length of the time period $m$ of the Gompertz curves (Table 4; Figs 3 and 4) was shorter for B-group than for A-group ascospores, except at temperature/wetness duration combinations of $10 / 16$, $10 / 24$ and $15 / 8\left({ }^{\circ} \mathrm{C} / \mathrm{h}\right)$.

There was evidence that increasing wetness duration above $24 \mathrm{~h}$ affected time to appearance of $50 \%$ of lesions on plants inoculated with both A-group and Bgroup ascospores at $10^{\circ} \mathrm{C}$ (Table 5 ). At $20^{\circ} \mathrm{C}$, the values of $t_{50}$ for B-group ascospores decreased with increasing wetness from 16 to $48 \mathrm{~h}$. For both A-group and B-group ascospores at $10^{\circ} \mathrm{C}$, the length of time period $m$ decreased at wetness durations above $24 \mathrm{~h}$, and at $15^{\circ} \mathrm{C}$ there was evidence of a rapid decrease in values of $m$ as wetness durations increased above $8 \mathrm{~h}$ (Table 4).

\section{Discussion}

Single-ascospore isolations made from the pieces of UK and Polish oilseed rape debris used as inoculum sources for these controlled-environment experiments 
(a)

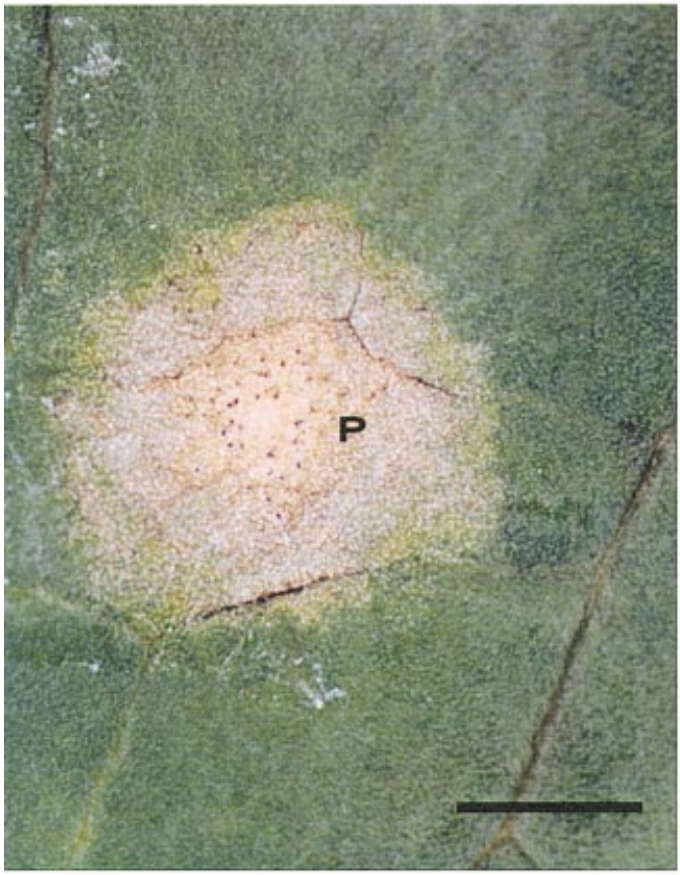

(b)

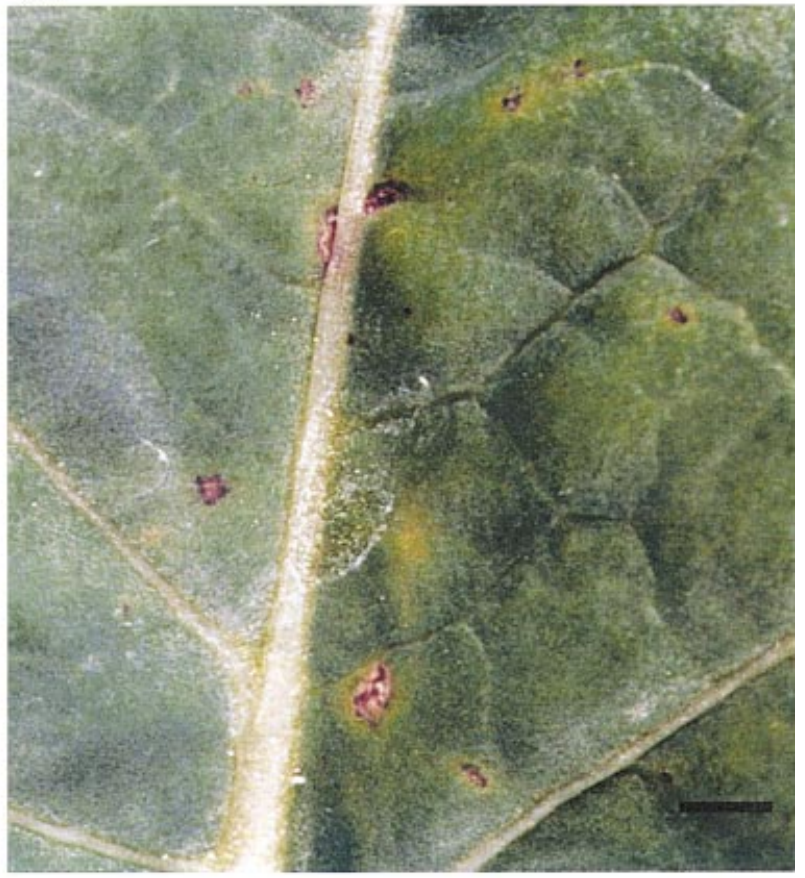

(c)

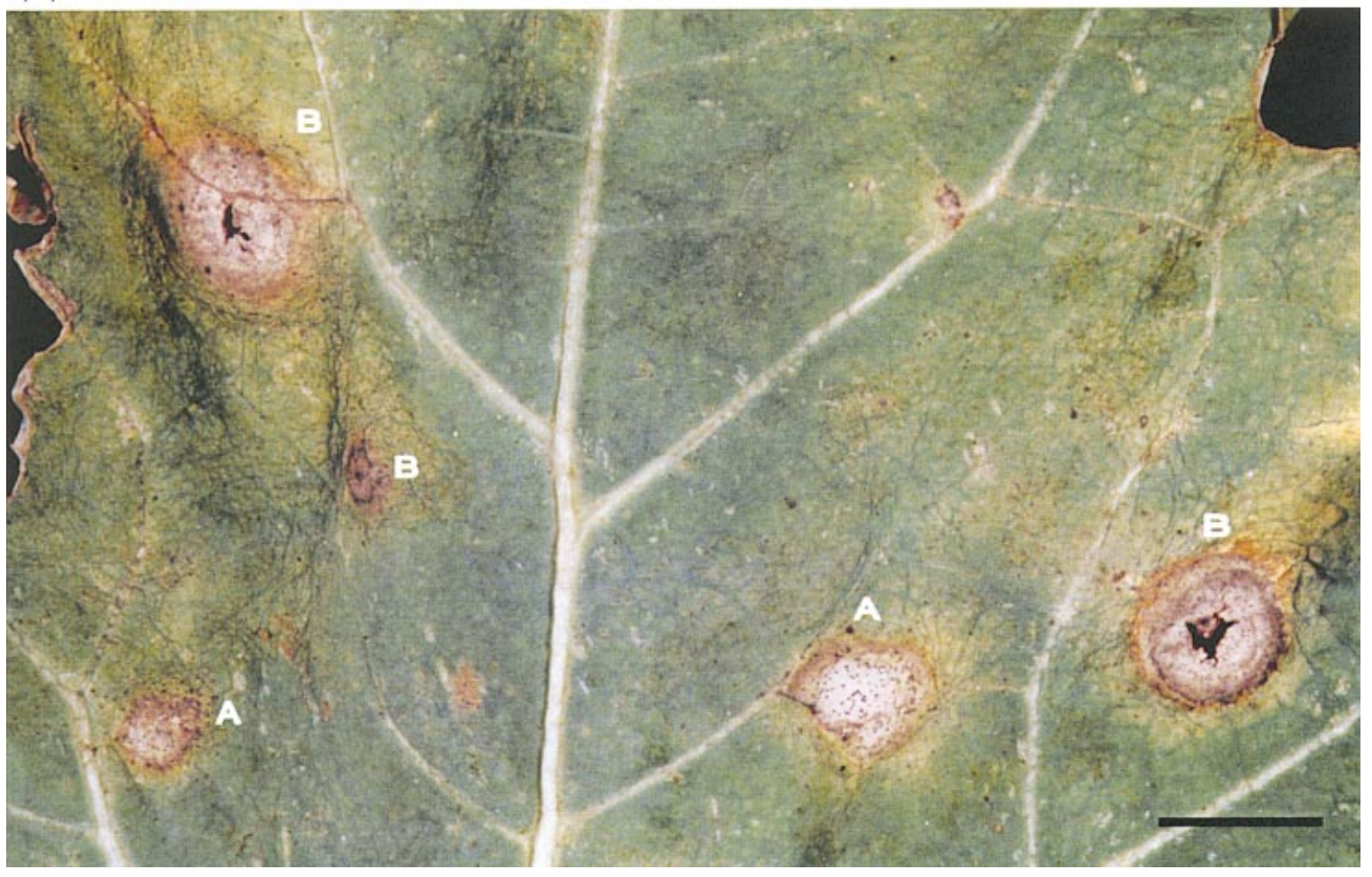

Figure 1 (a) Predominant type of lesions formed on oilseed rape leaves inoculated with $10^{3}$ ascospores $\mathrm{mL}^{-1}$ of A-group Leptosphaeria maculans; pale grey lesions with pycnidia $(P) 15$ days after inoculation at $15^{\circ} \mathrm{C}(\mathrm{bar}=0.4 \mathrm{~cm})$. (b) Predominant type of lesions formed on oilseed rape leaves inoculated with $10^{3}$ ascospores $\mathrm{mL}^{-1}$ of B-group L. maculans; small dark lesions 7 days after inoculation at $15^{\circ} \mathrm{C}(\mathrm{bar}=0.8 \mathrm{~cm}$ ). (c) Phoma leaf spot lesions on winter oilseed rape plants from field experiments at Rothamsted. Isolations from lesions showed that they were caused by A-group (A) and B-group (B) L. maculans (bar $=1.5 \mathrm{~cm}$ ). 
Table 3 Effects of temperature and wetness duration on maximum number of phoma leaf spot lesions produced on leaves of oilseed rape (cultivar Lipton) inoculated with ascospores of A-group or B-group Leptosphaeria maculans.

\begin{tabular}{|c|c|c|c|c|c|}
\hline \multirow{3}{*}{$\begin{array}{l}\text { Temperature } \\
\left({ }^{\circ} \mathrm{C}\right)\end{array}$} & \multirow{3}{*}{$\begin{array}{l}\text { Wetness } \\
\text { duration (h) }\end{array}$} & \multicolumn{4}{|c|}{ Number of lesions leaf $^{-1}$} \\
\hline & & \multicolumn{2}{|c|}{$\log _{10}$-transformed ${ }^{a}$} & \multicolumn{2}{|c|}{ Back-transformed means } \\
\hline & & A & $\mathrm{B}$ & A & $\mathrm{B}$ \\
\hline \multirow[t]{5}{*}{5} & 8 & $\star b$ & * & * & * \\
\hline & 16 & 0.06 & 0.02 & 0.15 & 0.05 \\
\hline & 24 & 0.21 & 0.03 & 0.60 & 0.08 \\
\hline & 48 & 0.46 & 0.11 & 1.90 & 0.29 \\
\hline & 72 & 0.72 & 0.17 & 4.27 & 0.48 \\
\hline \multirow[t]{5}{*}{10} & 8 & * & * & * & * \\
\hline & 16 & 0.16 & 0.11 & 0.45 & 0.30 \\
\hline & 24 & 0.49 & 0.18 & 2.06 & 0.50 \\
\hline & 48 & 0.83 & 0.43 & 5.75 & 1.69 \\
\hline & 72 & 1.13 & 0.67 & 12.42 & 3.66 \\
\hline \multirow[t]{4}{*}{15} & 8 & 0.16 & 0.12 & 0.44 & 0.32 \\
\hline & 16 & 0.44 & 0.14 & 1.77 & 0.37 \\
\hline & 24 & 0.75 & 0.32 & 4.63 & 1.09 \\
\hline & 48 & 1.36 & 0.72 & 22.13 & 4.19 \\
\hline \multirow[t]{4}{*}{20} & 8 & 0.14 & 0.06 & 0.39 & 0.14 \\
\hline & 16 & 0.37 & 0.13 & 1.33 & 0.34 \\
\hline & 24 & 0.71 & 0.21 & 4.11 & 0.62 \\
\hline & 48 & 0.97 & 0.71 & 8.36 & 4.11 \\
\hline $\operatorname{SED}(\max )^{\mathrm{c}}$ & & & $0 \cdot 196$ & & \\
\hline
\end{tabular}

${ }^{a}$ Number of lesions per leaf (four leaves per plant; four plants per treatment); mean of data from expts 1, 2, 3, and 4.

${ }^{\mathrm{b}}$ These treatment combinations were not tested.

'Estimated by restricted maximum likelihood estimation (REML); it was not possible to give d.f.

confirmed that the ascospores from stem pieces collected from field experiments at Rothamsted (UK ascospores) were predominantly (95\%) A-group, and the ascospores from stem pieces collected from field experiments in Poznan (Polish ascospores) were entirely B-group L. maculans. These controlled-environment experiments suggest that ascospores of both A-group and B-group L. maculans are able to infect oilseed rape leaves over a wide range of temperatures $\left(5-20^{\circ} \mathrm{C}\right)$ and leaf wetness durations $(8-72 \mathrm{~h})$. Previous work (Biddulph et al., 1999a) had shown that ascospores of L. maculans from UK winter oilseed rape debris (predominantly A-group) can infect oilseed rape over a range of temperatures and wetness durations. These controlled-environment experiments provide data for A-group ascospores that support those of Biddulph et al. (1999a). In addition, these experiments now provide detailed data on the infection conditions for ascospores of B-group L. maculans, and enable comparisons to be made between the infection conditions for the two groups.

Results from these controlled-environment experiments suggest that there are noticable differences between A-group and B-group L. maculans in the predominant type of leaf lesions formed on oilseed rape leaves inoculated with their ascospores. B-group (Polish) ascospores generally produced smaller lesions, often with a distinctive dark margin and light brown centre, containing considerably fewer pycnidia than the larger, pale grey lesions produced by A-group (UK) ascospores. Johnson \& Lewis (1994) had also observed that lesions formed on leaves of susceptible lines of winter oilseed rape inoculated with conidia of B-group (UK) $L$. maculans were smaller, with fewer pycnidia than lesions caused by A-group (UK) conidia. Similar differences between the two groups in the predominant type of leaf lesions were observed on winter oilseed rape crops from which isolations were made in France (Brun et al., 1997) and Germany (Thürwächter et al., 1999). Johnson \& Lewis (1994) and Brun et al. (1997) both reported some overlap in the appearance of leaf lesions caused by the two groups of L. maculans, similar to that observed at Rothamsted (Fig. 1c). Therefore some degree of caution should be applied when attempting to characterize individual leaf lesions as being caused by one of the two L. maculans groups. Confirmation by other tests is often necessary for accurate diagnosis (Williams \& Fitt, 1999).

Analyses of data from these controlled-environment experiments suggest that temperature is the main factor affecting the length of the incubation period $\left(t_{1}\right.$ or $\left.t_{50}\right)$ of both A-group and B-group L. maculans. Times to the appearance of the first leaf spot lesions and to the appearance of $50 \%$ of the lesions both decreased with increasing temperature from 5 to $20^{\circ} \mathrm{C}$, suggesting that after ascospore infection, phoma leaf spot lesions will develop more rapidly in winter oilseed rape crops in autumn or spring than in winter, as with light leaf spot 
Table 4 Parameters (estimated values) of Gompertz curves describing the maximum number of lesions per leaf ( $\mathrm{N}$ ) with time ( $t$, days after inoculation) on oilseed rape cv. Lipton inoculated with ascospores of A-group or B-group Leptosphaeria maculans

\begin{tabular}{|c|c|c|c|c|c|c|}
\hline \multicolumn{3}{|c|}{ Treatment } & \multicolumn{3}{|c|}{ Parameter ${ }^{\mathrm{a}}$ estimates } & \multirow[b]{2}{*}{$\begin{array}{l}\text { Percentage variance } \\
\text { (accounted for) }\end{array}$} \\
\hline Group & $\begin{array}{l}\text { Temperature } \\
\left({ }^{\circ} \mathrm{C}\right)\end{array}$ & $\begin{array}{l}\text { Wetness } \\
\text { duration (h) }\end{array}$ & c & 1 & $m$ & \\
\hline \multirow[t]{4}{*}{ A } & \multirow[t]{4}{*}{5} & 16 & $0.73(0.82)^{b}$ & $0.02(0.004)$ & $25.90(20.1)$ & 54.6 \\
\hline & & 24 & $1.67(0.54)$ & $0.09(0.02)$ & $23.71(2.75)$ & 82.3 \\
\hline & & 48 & $5.77(1.10)$ & $0.32(0.04)$ & $23.01(1.57)$ & 87.3 \\
\hline & & 72 & $16.07(4.64)$ & $0.80(0.12)$ & $22.69(2.58)$ & 76.2 \\
\hline \multirow[t]{4}{*}{ B } & \multirow[t]{4}{*}{5} & 16 & $0.57(0.02)$ & $0.10(0.02)$ & $16.06(0.30)$ & 98.3 \\
\hline & & 24 & $0.23(0.01)$ & $0.06(0.02)$ & $16.86(0.35)$ & 93.1 \\
\hline & & 48 & $0.65(0.05)$ & $0.07(0.02)$ & $14.48(0.78)$ & 72.8 \\
\hline & & 72 & $1.46(0.54)$ & $0.05(0.01)$ & $17.44(4.73)$ & 55.9 \\
\hline \multirow[t]{4}{*}{ A } & \multirow[t]{4}{*}{10} & 16 & $0.71(0.04)$ & $0.10(0.03)$ & $14.16(0.55)$ & 71.5 \\
\hline & & 24 & $3.52(0.25)$ & $0.22(0.02)$ & $17.50(0.60)$ & 92.8 \\
\hline & & 48 & $11.46(0.22)$ & $1.32(0.10)$ & $14.55(0.16)$ & 97.3 \\
\hline & & 72 & $23.88(0.39)$ & $2.80(0.17)$ & $14.81(0.14)$ & 98.1 \\
\hline \multirow[t]{4}{*}{ B } & \multirow[t]{4}{*}{10} & 16 & $0.60(0.11)$ & $0.03(0.01)$ & $15.27(1.98)$ & 72.2 \\
\hline & & 24 & $1.91(0.35)$ & $0.09(0.01)$ & $18.75(1.78)$ & 86.0 \\
\hline & & 48 & $3.82(0.22)$ & $0.26(0.04)$ & $8.18(0.64)$ & 76.1 \\
\hline & & 72 & $6.15(0.20)$ & $0.60(0.09)$ & $7.12(0.41)$ & 79.3 \\
\hline \multirow[t]{4}{*}{ A } & \multirow[t]{4}{*}{15} & 8 & $0.90(0.35)$ & $0.08(0.02)$ & $11.20(1.94)$ & 72.7 \\
\hline & & 16 & $2.75(0.11)$ & $0.56(0.07)$ & $9.49(0.15)$ & 97.1 \\
\hline & & 24 & $8.83(0.36)$ & $1.39(0.14)$ & $9.17(0.17)$ & 97.4 \\
\hline & & 48 & $36.67(0.73)$ & $10.12(0.91)$ & $9.31(0.09)$ & 98.2 \\
\hline \multirow[t]{4}{*}{ B } & \multirow[t]{4}{*}{15} & 8 & $1.74(3.73)$ & $0.05(0.04)$ & $14.80(26.4)$ & 45.3 \\
\hline & & 16 & $0.93(0.12)$ & $0.09(0.03)$ & $4.16(0.79)$ & 69.1 \\
\hline & & 24 & $2.03(0.12)$ & $0.28(0.04)$ & $4.90(0.33)$ & 85.9 \\
\hline & & 48 & $7.06(0.15)$ & $1.47(0.13)$ & $4.88(0.12)$ & 96.2 \\
\hline \multirow[t]{4}{*}{ A } & \multirow[t]{4}{*}{20} & 8 & $1.54(1.12)$ & $0.07(0.02)$ & $8.84(6.60)$ & 51.8 \\
\hline & & 16 & $2.02(0.06)$ & $0.39(0.04)$ & $6.82(0.17)$ & 96.0 \\
\hline & & 24 & $8.78(0.22)$ & $1.87(0.17)$ & $7.14(0.13)$ & 97.2 \\
\hline & & 48 & $17.88(0.30)$ & $4.60(0.33)$ & $6.58(0.09)$ & 98.2 \\
\hline \multirow[t]{4}{*}{ B } & \multirow[t]{4}{*}{20} & 8 & *c & * & * & * \\
\hline & & 16 & $0.54(0.05)$ & $0.10(0.04)$ & $3.76(0.61)$ & 59.8 \\
\hline & & 24 & $1.04(0.09)$ & $0.12(0.03)$ & $3.70(0.54)$ & 68.5 \\
\hline & & 48 & $5.62(0.07)$ & $1.59(0.14)$ & $3.29(0.09)$ & 95.6 \\
\hline
\end{tabular}

${ }^{\text {a }}$ arameters: maximum number of lesions per leaf $(c)$, maximum rate of increase in the number of lesions per leaf per day $(I)$ and day on which the rate of increase in the number of lesions per leaf was maximum $(m)$ were estimated by fitting Gompertz curves $(N=c \exp \{-\exp [-(/ . e / c)(t-m)]\})$ to scaled data at each temperature and wetness duration. Data were scaled to the mean maximum number of lesions from the four experiments for each temperature/wetness treatment.

${ }^{b}$ Standard errors in parentheses.

${ }^{\mathrm{C}}$ Too few lesions developed to fit a curve.

(Figueroa et al., 1995; Gilles et al., 2000). The results of the controlled environment experiments of Hammond et al. (1985), in which the time between the appearance of leaf lesions and the appearance of stem lesions was 77 days at $18^{\circ} \mathrm{C}$ and 175 days at $3^{\circ} \mathrm{C}$, suggest that temperature similarly influences the rate of growth of L. maculans down the leaf petiole. In these Rothamsted controlled-environment experiments, time from inoculation to the appearance of leaf spot lesions was used as an estimate of the incubation period. Data from these experiments suggest that the incubation period of Bgroup L. maculans, between infection and the appearance of lesions, may be shorter than the incubation period of A-group L. maculans. These results agree with those obtained in experiments investigating the early stages of colonization of oilseed rape leaves when
A-group and B-group L. maculans had similar infection pathways, but B-group infections developed more rapidly and caused more rapid necrosis, visible as macroscopic lesions, than A-group infections (Johnson $\&$ Lewis, 1994). However, investigations on the germination of ascospores suggest that there may be differences in the rate of ascospore germination between A-group and B-group L. maculans (Y.J. Huang, IACRRothamsted, Harpenden, UK, personal communication) before infection occurs. This suggests that the differences in time from inoculation to appearance of symptoms observed in these controlled-environment experiments might have occurred as a result of differences between A-group and B-group L. maculans in the rate of ascospore germination and infection, and not as a result of differences in actual incubation 

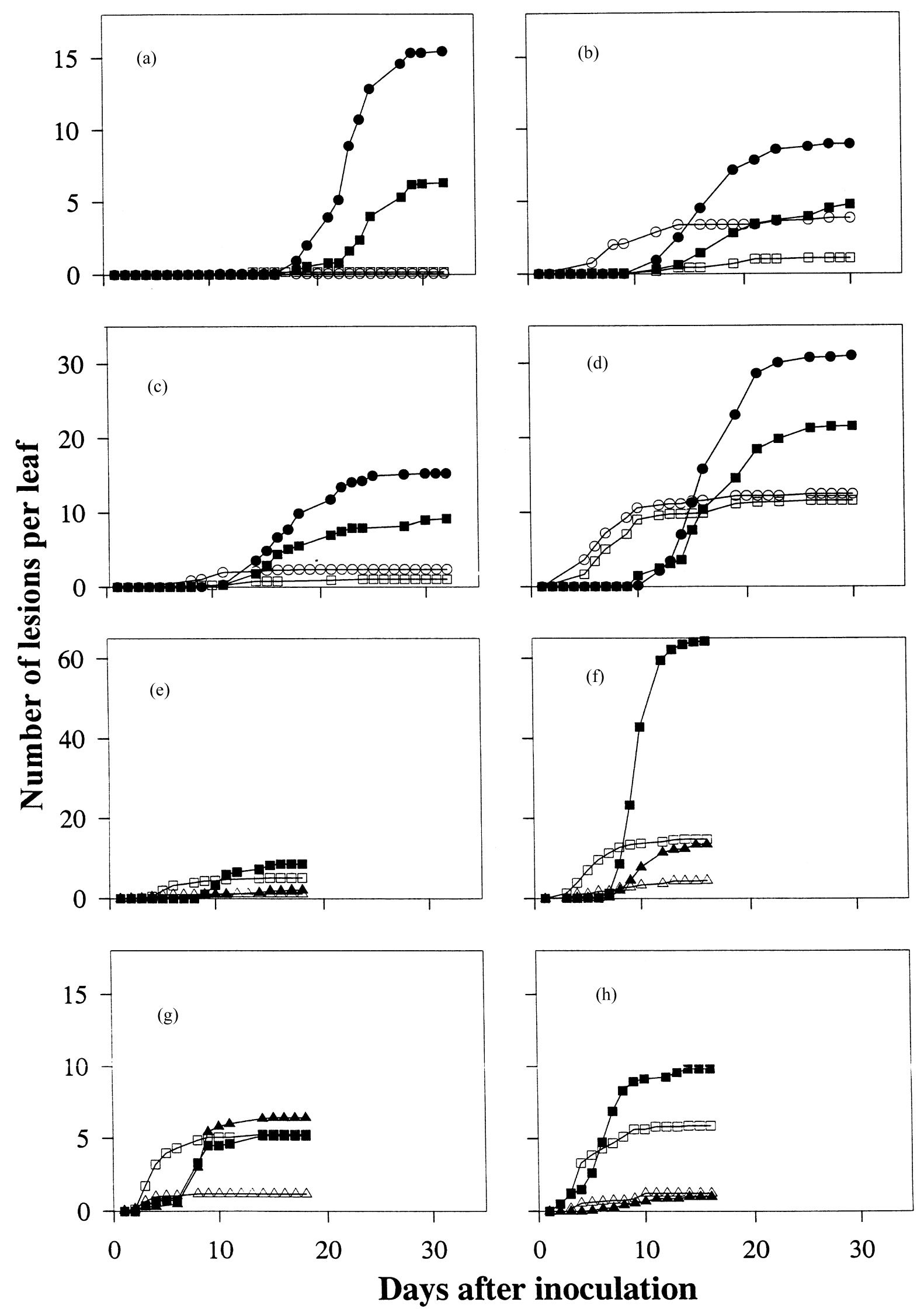


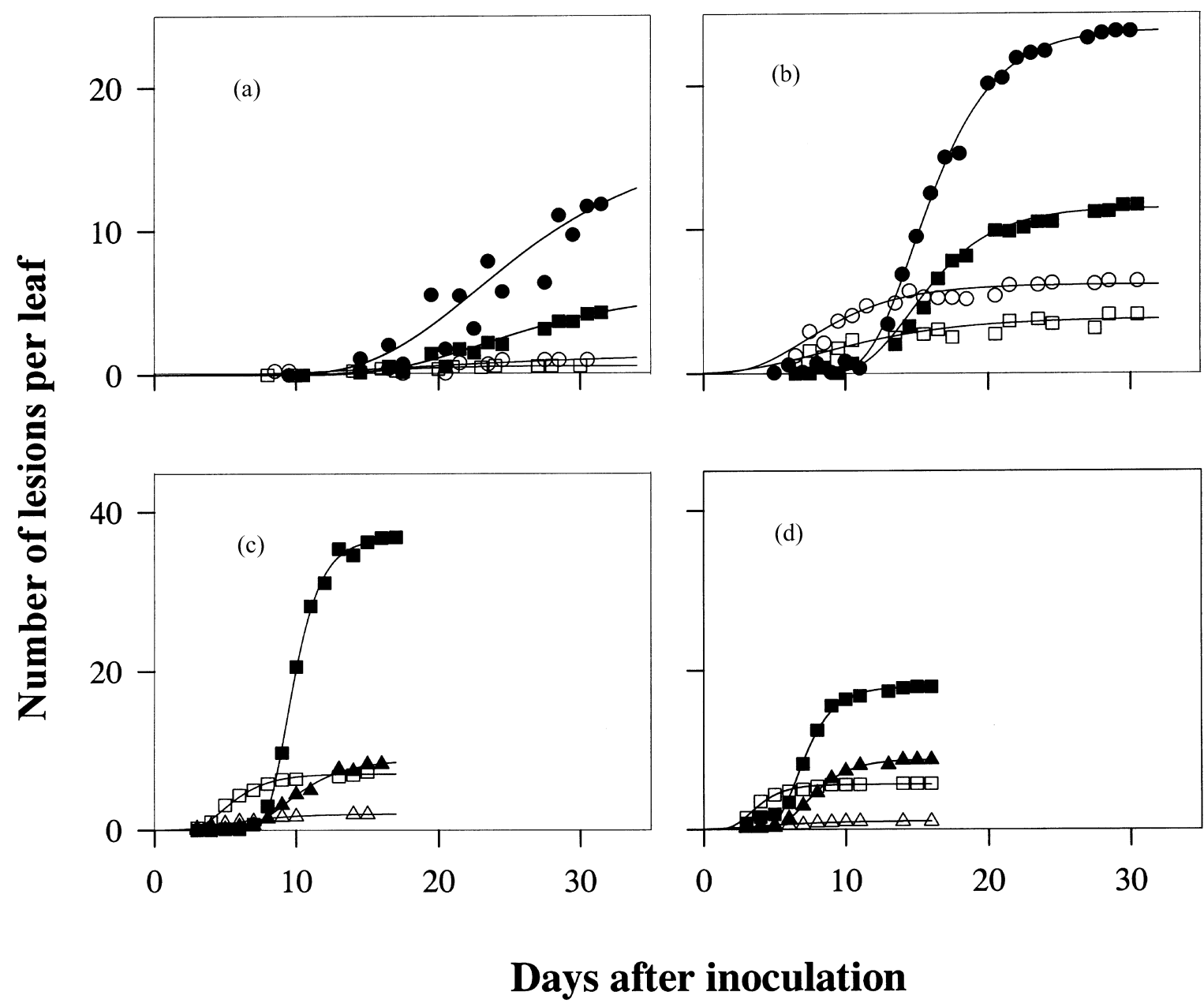

Figure 3 Gompertz curves fitted to data for changes in number of lesions per leaf with time on oilseed rape plants inoculated with ascospores of A-group $(\boldsymbol{\Lambda}, \boldsymbol{\square}, \bullet)$ or B-group $(\Delta, \square, 0)$ Leptosphaeria maculans with wetness durations of $24 \mathrm{~h}(\boldsymbol{\Lambda}, \Delta), 48 \mathrm{~h}(\boldsymbol{\square}, \square)$ or $72 \mathrm{~h}$ $(\bullet, O)$ at temperatures of $5^{\circ} \mathrm{C}(\mathrm{a}), 10^{\circ} \mathrm{C}(\mathrm{b}), 15^{\circ} \mathrm{C}(\mathrm{c})$ or $20^{\circ} \mathrm{C}(\mathrm{d})$. The Gompertz curves $(N=c \exp \{-\exp [-(I . e / \mathrm{c})(t-m)]\})$ were fitted to scaled data for number of lesions per leaf $(N)$ with time after inoculation $(t)$ at each temperature and wetness duration (Table 4). The parameters $c, l$ and $m$ are the maximum number of lesions per leaf, the maximum rate of increase per day in the number of lesions per leaf, and the day on which the number of lesions per leaf was maximum, respectively. Lesions were assessed on four leaves per plant on four plants per treatment; data points are means of two to four replicates, and lines are fitted values calculated from data scaled to the mean maximum number of lesions, from the four experiments for each temperature/wetness treatment.

periods (time from infection to the appearance of lesions).

These results indicate that the maximum numbers of leaf lesions produced by ascospores of both A-group and B-group L. maculans were influenced by both temperature and wetness duration. The efficiency of infection by both A-group and B-group ascospores was greatest at $15-20^{\circ} \mathrm{C}$, with most lesions produced when wetness duration was at least $48 \mathrm{~h}$, as observed by Biddulph et al. (1999a); Biddulph et al. (1999b). A minimum period of $8 \mathrm{~h}$ leaf wetness was required for infection. Increasing wetness periods up to an optimum of $48 \mathrm{~h}$ increased the probability of infection and lesion formation in compatible interactions. Furthermore, the results suggest that ascospores of A-group L. maculans were more infective than those of B-group L. maculans. This could explain the greater number of leaf lesions produced by ascospores of A-group L. maculans than by B-group ascospores for all temperature/wetness treatments tested in these controlled-environment experiments. Jedryczka et al. (1999) suggested that UK isolates (A-group) were more pathogenic to winter

Figure 2 Changes with time in the number of phoma leaf lesions on oilseed rape plants inoculated with ascospores of A-group ( $\mathbf{\Lambda}$, $\mathbf{\square}$, $\boldsymbol{\bullet}$ ) or B-group $(\Delta, \square, 0)$ Leptosphaeria maculans in three experiments with wetness durations of $24 \mathrm{~h}(\boldsymbol{\Lambda}, \Delta), 48 \mathrm{~h}(\boldsymbol{\square}, \square)$ or $72 \mathrm{~h}(\bullet, 0)$ at temperatures of $5^{\circ} \mathrm{C}(\mathrm{a}, \mathrm{b}), 10^{\circ} \mathrm{C}(\mathrm{c}, \mathrm{d}), 15^{\circ} \mathrm{C}(\mathrm{e}, \mathrm{f})$ or $20^{\circ} \mathrm{C}(\mathrm{g}, \mathrm{h})$. Lesions were assessed on four leaves per plant on four plants per treatment. Data illustrated are from experiments $1(\mathrm{a}, \mathrm{c}, \mathrm{e}, \mathrm{g}), 3(\mathrm{~h})$ and $4(\mathrm{~b}, \mathrm{~d}, \mathrm{f})$. 

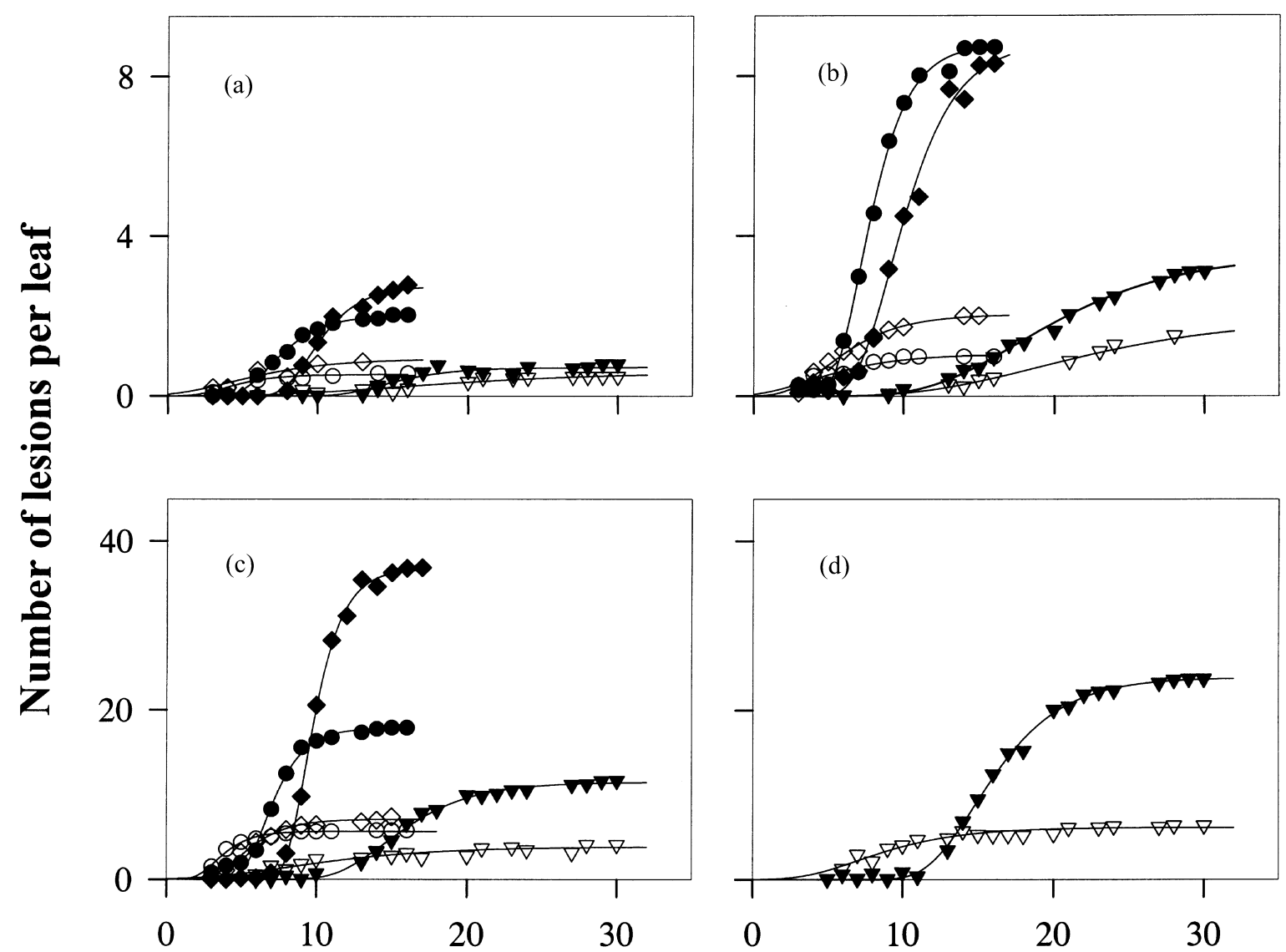

\section{Days after inoculation}

Figure 4 Gompertz curves fitted to data for changes in numbers of lesions per leaf on oilseed rape plants inoculated with ascospores of A-group $(\mathbf{\nabla}, \bullet)$ or B-group $(\nabla, \diamond, 0)$ Leptosphaeria maculans at temperatures of $10^{\circ} \mathrm{C}(\mathbf{\nabla}, \nabla), 15^{\circ} \mathrm{C}(\bullet, \diamond)$ or $20^{\circ} \mathrm{C}(\bullet, 0)$, with wetness durations of $16 \mathrm{~h}(\mathrm{a}), 24 \mathrm{~h}(\mathrm{~b}), 48 \mathrm{~h}$ (c) or $72 \mathrm{~h}$ (d). The Gompertz curves $(N=c \exp \{-\exp [-(\mathrm{l} . \mathrm{e} / \mathrm{c})(t-m)]\})$ were fitted to scaled data for number of lesions per leaf $(N)$ with time after inoculation ( $t)$ (Table 4). (See Fig. 3 for details).

oilseed rape than Polish isolates (B-group), based on results from soilborne infection of seedling hypocotyls in pot experiments. The ability of A-group L. maculans to produce phytotoxins (Koch et al., 1989; Williams, 1992; Jedryczka et al., 1999; Williams \& Fitt, 1999) may explain these differences.

The differences between the two L. maculans groups in the symptoms they produce on oilseed rape leaves and their growth into stem tissues may account for some of the differences in the epidemiology of stem canker between the UK and Poland, as currently understood. In Poland (where the B-group is predominant), phoma leaf spot symptoms are not often seen in crops in the autumn, and the disease does not become noticable until it is observed on stems in the spring (Frencel et al., 1991; Jedryczka et al., 1999), unlike in the UK (A-group predominant). Since B-group leaf spot lesions are often less distinctive than A-group leaf spot lesions, even at higher temperatures, it may be much more difficult to detect the leaf spot phase of the disease in Poland than in the UK, especially as autumn and winter temperatures are lower in Poland. The climatic differences between the two countries may have an impact on the length of time taken for fungal growth from the leaf to the stem (Hammond et al., 1985) and hence on the timing of stem infection development.

As the B-group of L. maculans is also present in UK populations of the fungus (Hammond \& Lewis, 1986; Johnson \& Lewis, 1994; Jedryczka et al., 1999), the importance of this group in the epidemiology of the disease in the UK may have been underestimated. Indeed, Johnson \& Lewis (1994) reported the progress of natural epidemics of mixtures of A-group and B-group $L$. maculans in the UK. Their results suggest that there may be differences between the two groups in the timing of the epidemic onset. These differences may be related to changes in the production and maturation of inoculum (ascospores) of the two groups during the season. Comparisons between the biology and epidemiology of the two groups merit further attention. 
Table 5 Effects of temperature and wetness duration on the incubation period, estimated as the times from inoculation to the appearance of the first phoma leaf spot lesions on oilseed rape cv. Lipton leaves inoculated with ascospores of A-group or B-group Leptosphaeria maculans or to the appearance of $50 \%$ of the lesions

\begin{tabular}{|c|c|c|c|c|c|}
\hline \multirow{2}{*}{$\begin{array}{l}\text { Temperature } \\
\left({ }^{\circ} \mathrm{C}\right)\end{array}$} & \multirow{2}{*}{$\begin{array}{l}\text { Wetness } \\
\text { duration (h) }\end{array}$} & \multicolumn{2}{|c|}{$\begin{array}{l}\text { Days to first lesions } \\
\text { (fitted values) }^{\text {a }}\end{array}$} & \multicolumn{2}{|c|}{$\begin{array}{l}\text { Days to } 50 \% \text { of lesions } \\
\text { (fitted values) }\end{array}$} \\
\hline & & A & B & A & B \\
\hline \multirow[t]{5}{*}{5} & 8 & $\star \mathrm{b}$ & * & * & * \\
\hline & 16 & 13.0 & 16.0 & 18.7 & 16.8 \\
\hline & 24 & 15.0 & 16.5 & 24.5 & $t^{c}$ \\
\hline & 48 & 15.5 & 14.3 & 21.8 & 18.7 \\
\hline & 72 & 13.8 & 14.8 & 22.7 & $\dagger$ \\
\hline \multirow[t]{5}{*}{10} & 8 & * & * & * & * \\
\hline & 16 & 8.3 & 7.8 & 18.6 & 12.4 \\
\hline & 24 & 7.5 & 11.0 & 18.4 & 20.0 \\
\hline & 48 & 9.3 & 6.5 & 15.6 & 11.7 \\
\hline & 72 & 8.0 & 5.8 & 15.9 & 9.2 \\
\hline \multirow[t]{4}{*}{15} & 8 & 8.0 & 4.3 & 9.1 & 6.5 \\
\hline & 16 & 6.3 & 3.0 & 10.2 & 6.7 \\
\hline & 24 & 2.7 & 3.0 & 10.3 & 6.1 \\
\hline & 48 & 5.7 & 3.0 & 9.8 & 5.6 \\
\hline \multirow[t]{4}{*}{20} & 8 & 3.7 & 8.5 & 5.4 & $\dagger$ \\
\hline & 16 & 4.0 & 2.7 & 7.8 & 8.7 \\
\hline & 24 & 3.0 & 2.3 & 8.0 & 4.8 \\
\hline & 48 & 3.0 & 2.7 & 7.2 & 3.7 \\
\hline $\operatorname{SED}(\max )^{d}$ & & 5.09 & & 4.85 & \\
\hline
\end{tabular}

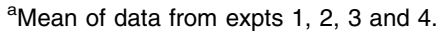

${ }^{\mathrm{b}}$ These treatment combinations were not tested.

${ }^{\mathrm{c}}$ Too few lesions developed to estimate a reliable value.

dEstimated by restricted maximum likelihood estimation (REML); it was not possible to give d.f.

\section{Acknowledgements}

We thank the European Union (FAIR contract CT961669; coordinator M.H. Balesdent), the UK Ministry of Agriculture, Fisheries and Food, and the Biotechnology and Biological Sciences Research Council for funding this research. We are grateful to Y.J. Huang for providing us with information on ascospore germination and to T. Gilles for helpful comments on this manuscript.

\section{References}

Anonymous, 1997. NIAB Oilseeds Variety Handbook. Cambridge, UK: NIAB.

Balesdent MH, Gall C, Robin P, Rouxel T, 1992. Intraspecific variation in soluble mycelial protein and esterase patterns of Leptosphaeria maculans French isolates. Mycological Research 96, 677-84.

Biddulph JE, Fitt BDL, Leech PK, Welham SJ, Gladders P, 1999a. Effects of temperature and wetness duration on infection of oilseed rape leaves by ascospores of Leptosphaeria maculans (stem canker). European Journal of Plant Pathology 105, 769-81.

Biddulph JE, Fitt BDL, Jedryczka M, West JS, Welham SJ, 1999b. Effects of temperature and wetness duration on infection of oilseed rape by ascospores of A-group or Bgroup Leptosphaeria maculans (stem canker). Abstract. In:
Proceedings of the 10th International Rapeseed Congress, Canberra, Australia, 129.

Brun H, Levivier S, Eber F, Renard M, Chèvre AM, 1997. Electrophoretic analysis of natural populations of Leptosphaeria maculans directly from leaf lesions. Plant Pathology 46, 147-54.

Figueroa L, Fitt BDL, Shaw MW, McCartney HA, Welham SJ, 1995. Effects of temperature on the development of light leaf spot (Pyrenopeziza brassicae) on oilseed rape (Brassica napus). Plant Pathology 44, 51-62.

Fitt BDL, Gladders P, Turner JA, Sutherland KG, Welham SJ, Davies JML, 1997. Prospects for developing a forecasting scheme to optimize use of fungicides for disease control on winter oilseed rape in the UK. Aspects of Applied Biology: Optimising Pesticide Applications 48, 135-42.

Frencel I, Lewartowska E, Jedryczka M, 1991. The spectrum and severity of fungal diseases in field infections of oilseed rape in Poland. A review of the 1980s. International Organisation for Biological Control Bulletin 14, 137-40.

Gilles T, Fitt BDL, Kennedy R, Welham SJ, Jeger MJ, 2000. Effects of temperature and wetness duration on conidial infection, latent period and asexual sporulation of Pyrenopeziza brassicae on leaves of oilseed rape. Plant Pathology 49, 498-508.

Gladders P, Musa TM, 1979. The development of Leptosphaeria maculans in winter oilseed rape and its implications for disease control. Proceedings of the British Crop Protection Conference - Pests and Diseases, 129-36. 
Gladders P, Musa TM, 1980. Observations on the epidemiology of Leptosphaeria maculans stem canker in winter oilseed rape. Plant Pathology 29, 28-37.

Gladders P, Symonds BV, 1995. Occurrence of canker (Leptosphaeria maculans) in winter oilseed rape in eastern England 1977-93. International Organisation for Biological Control Bulletin 18, 1-11.

Gladders P, Symonds BV, Hardwick NV, Sansford CE, 1998. Opportunities to control canker (Leptosphaeria maculans) in winter oilseed rape by improved spray timing. International Organisation for Biological Control Bulletin 21, 111-20.

Hammond KE, Lewis BG, 1986. The timing and sequence of events leading to stem canker disease in populations of Brassica napus var. oleifera in the field. Plant Pathology 35, 551-64.

Hammond KE, Lewis BG, Musa TM, 1985. A systemic pathway in the infection of oilseed rape plants by Leptosphaeria maculans. Plant Pathology 34, 557-65.

Humpherson-Jones FM, 1983. Pathogenicity studies on isolates of Leptosphaeria maculans from brassica seed production crops in south-east England. Annals of Applied Biology 103, $37-44$.

Humpherson-Jones FM, 1986. The occurrence of virulent pathotypes of Leptosphaeria maculans in brassica seed crops in England. Plant Pathology 35, 224-31.

Jedryczka M, Rouxel T, Balesdent MH, Mendes-Pereira E, Bertrandy J, 1997. Molecular characterisation of Polish Phoma lingam isolates. Cereal Research Communications 25, 279-83.

Jedryczka M, Fitt BDL, Kachlicki P, Lewartowska E, Balesdent MH, Rouxel T, 1999. Comparison between Polish and United Kingdom populations of Leptosphaeria maculans, cause of stem canker of winter oilseed rape. Zeitschrift für Pflanzenkrankheiten und Pflanzenschutz 106, 608-17.

Johnson RD, Lewis BG, 1990. DNA polymorphism in Leptosphaeria maculans. Physiological and Molecular Plant Pathology 37, 417-24.

Johnson RD, Lewis BG, 1994. Variation in host range, systemic infection and epidemiology of Leptosphaeria maculans. Plant Pathology 43, 269-77.

Koch E, Badawy HMA, Hoppe HH, 1989. Differences between aggressive and non-aggressive single spore lines of Leptosphaeria maculans in cultural characteristics and phytotoxin production. Journal of Phytopathology 124, 5262.

McGee DC, Petrie GA, 1978. Variability of Leptosphaeria maculans in relation to blackleg of oilseed rape. Phytopathology 68, 625-30.

Payne RW, Lane PW, Digby PGN, Harding SA, Leech PK, Morgan GW, Todd AD, Thompson R, Tunnicliffe Wilson G, Welham SJ, White RP, 1993. Genstat 5 Release 3 Reference Manual. Oxford, UK: Clarendon Press.

Poisson B, Pérès A, 1999. Studies related to maturation of Leptosphaeria maculans pseudothecia on oilseed stubbles with stem canker. Abstract. In: Proceedings of the 10th International Rapeseed Congress, Canberra, Australia, 134.

Somda I, Renard M, Brun H, 1996. Morphology, pathogenicity and isozyme variation amongst French isolates of Leptosphaeria maculans recovered from Brassica juncea cv. Picra. Plant Pathology 45, 1090-8.

Sylvester-Bradley R, Makepeace RJ, 1985. Revision of a code for stages of development in oilseed rape (Brassica napus L.). Aspects of Applied Biology: Field Trials Methods and Data Handling 10, 395-400.

Taylor JL, Borgmann IE, Séguin-Swartz G, 1991. Electrophoretic karyotyping of Leptosphaeria maculans differentiates highly virulent from weakly virulent isolates. Current Genetics 19, 273-7.

Thürwächter F, Garbe V, Hoppe H-H, 1999. Ascospore discharge, leaf infestation and variations in pathogenicity as criteria to predict impact of Leptosphaeria maculans on oilseed rape. Journal of Phytopathology 147, 215-22.

West JS, Biddulph JE, Fitt BDL, Gladders P, 1999. Epidemiology of Leptosphaeria maculans in relation to forecasting stem canker severity on winter oilseed rape in the UK. Annals of Applied Biology 135, 535-46.

Williams PH, 1992. Biology of Leptosphaeria maculans. Canadian Journal of Plant Pathology 14, 30-5.

Williams RH, Fitt BDL, 1999. Differentiating A and B groups of Leptosphaeria maculans, causal agent of stem canker (blackleg) of oilseed rape. Plant Pathology 48, 161-75.

Zhou Y, Fitt BDL, Welham SJ, Gladders P, Sansford CE, West JE, 1999. Effects of severity and timing of stem canker (Leptosphaeria maculans) symptoms on yield of winter oilseed rape (Brassica napus) in the UK. European Journal of Plant Pathology 105, 715-28. 